\title{
Detecting and characterizing dead wood using terrestrial laser scanning
}

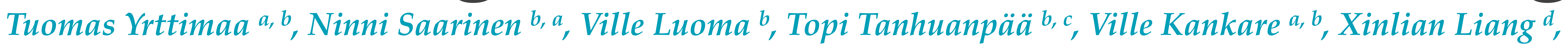
Juha Hyyppä ${ }^{d}$, Markus Holopainen ${ }^{b}$, Mikko Vastaranta ${ }^{a}$

a School of Forest Sciences, University of Eastern Finland

Department of Forest Sciences, University of Helsinki

Department of Geographical and Historical Studies, University of Eastern Finland

Department of Remote Sensing and Photogrammetry, Finnish Geospatial Research Institute

Published online 16 March 2019 @ ISPRS Photogrammetry and Remote Sensing (151), pp. 76-90.

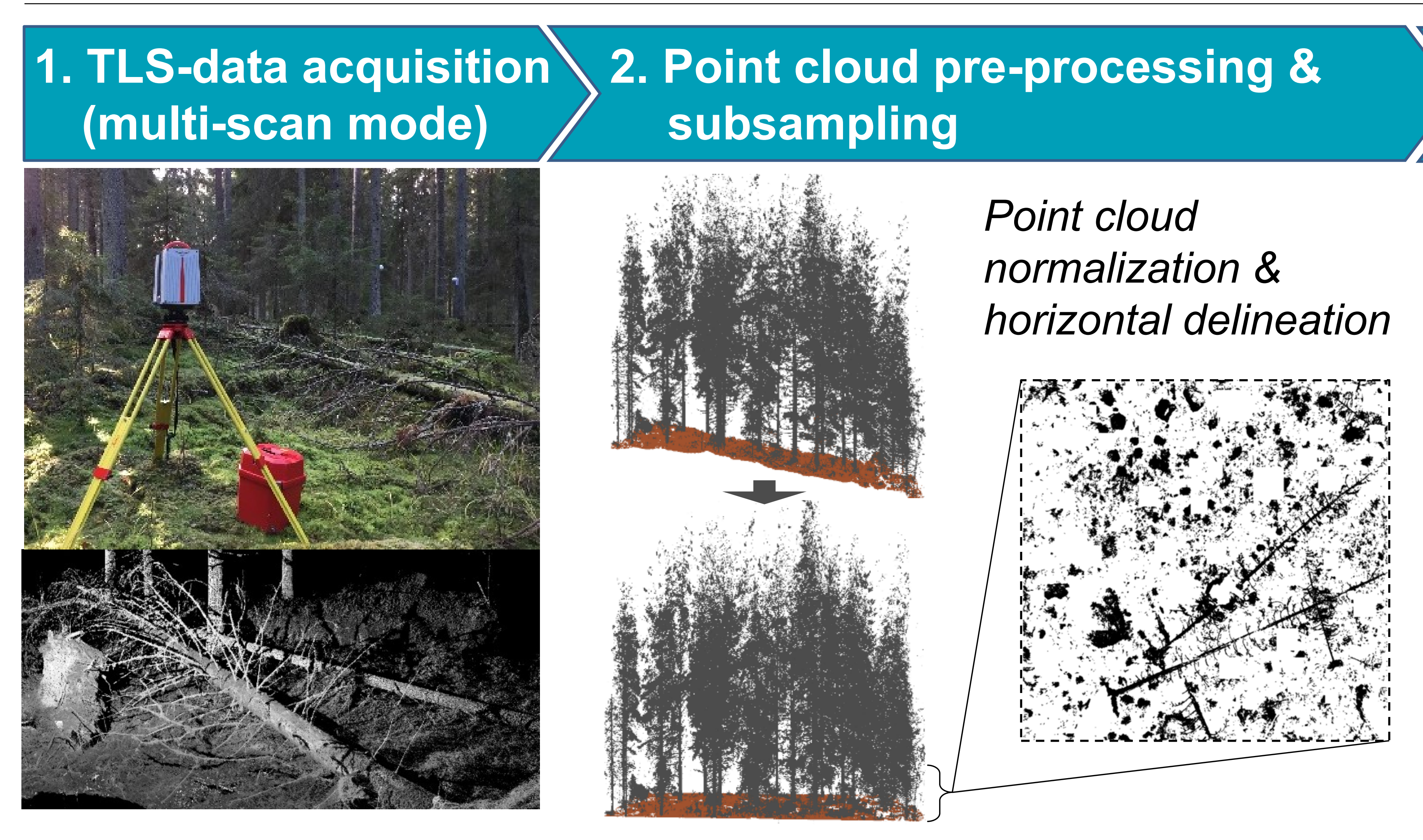

Background and objectives

Dead wood is a key forest structural component for maintaining biodiversity and storing carbon. Despite its important role in a forest ecosystem, quantifying dead wood alongside standing trees has often neglected when investigating the feasibility of terrestrial laser scanning (TLS) in forest inventories.

The objective of this study was therefore to develop an automatic method for detecting and characterizing downed dead wood.

\section{Materials and methods}

Study materials consist of multi-scan TLS data collected from 20 sample plots ( $32 \mathrm{~m} \times 32 \mathrm{~m}$ ) and reference measurements on dead wood trunks $(n=304)$ with mid-diameter $\geq 5 \mathrm{~cm}$.

Downed dead wood trunks were detected based on their geometric properties. Cylindrical point cloud structures elevating from the ground were filtered and rasterized, and elliptical raster segments were classified as dead wood trunks. Trunk properties were aggregated to plot-level dead wood attributes. The method description is summarized in the figure above.

\section{Detection of downed dead} wood

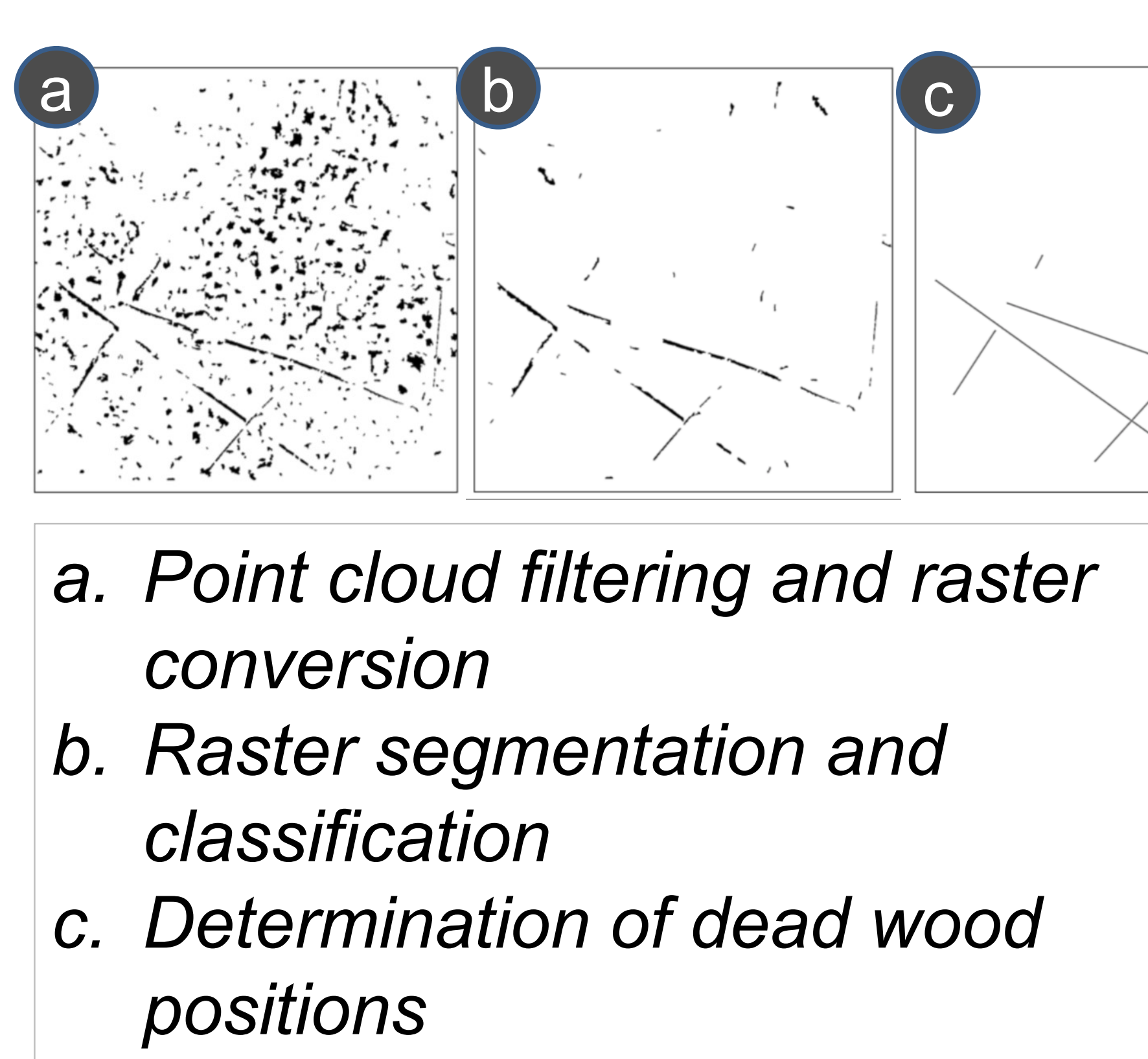

4. Dead wood metrics extraction

\section{Results and conclusions}

$>68 \%$ of the total volume of downed dead wood was detected automatically (Table 1).

$>$ Visual interpretation of point clouds improved dead wood volume detection accuracy to $83 \%$.

Large dead wood trunks were detected more reliably than small-diameter dead wood.

$>$ Dimension-related dead wood quality attributes (i.e. mid-diameter, length and volume) were estimated with an adequate accuracy (e.g. $6 \mathrm{~cm}$ RMSE for mid-diameter) considering the challenging conditions near the forest floor compared to standing trees.

Results of this study strengthen the feasibility of TLS-based approaches in mapping biodiversity indicators by demonstrating an improved performance in quantifying ecologically most valuable downed dead wood in diverse southern boreal forest conditions.

Table 1. Accuracy in dead wood detection. Plot-level variation in parenthesis.

\begin{tabular}{|c|c|c|c|} 
& Completeness & Correctness & Detected volume \\
\hline TLS-auto & $33 \%(0-60 \%)$ & $76 \%(50-100 \%)$ & $68 \%(0-92 \%)$ \\
\hline TLS-visual & $72 \%(33-100 \%)$ & $75 \%(45-100 \%)$ & $83 \%(11-100 \%)$ \\
\hline
\end{tabular}

\section{Contact:}

> Tuomas Yrttimaa // tuomas.yrttimaa@uef.fi

> Mikko Vastaranta // mikko.vastaranta@uef.fi

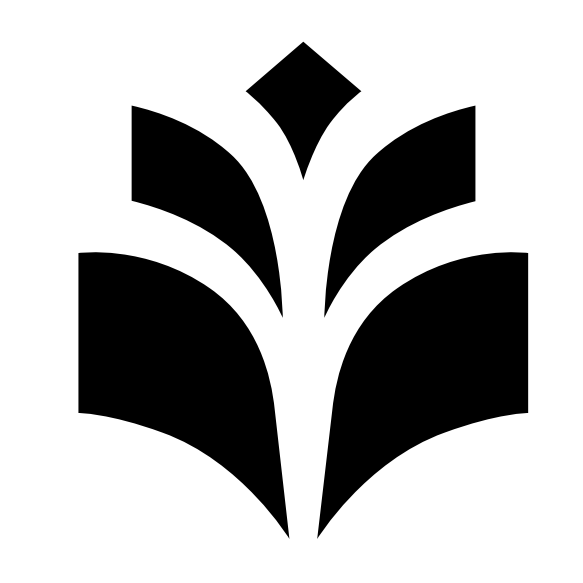

UNIVERSITYOF EASTERN FINLAND

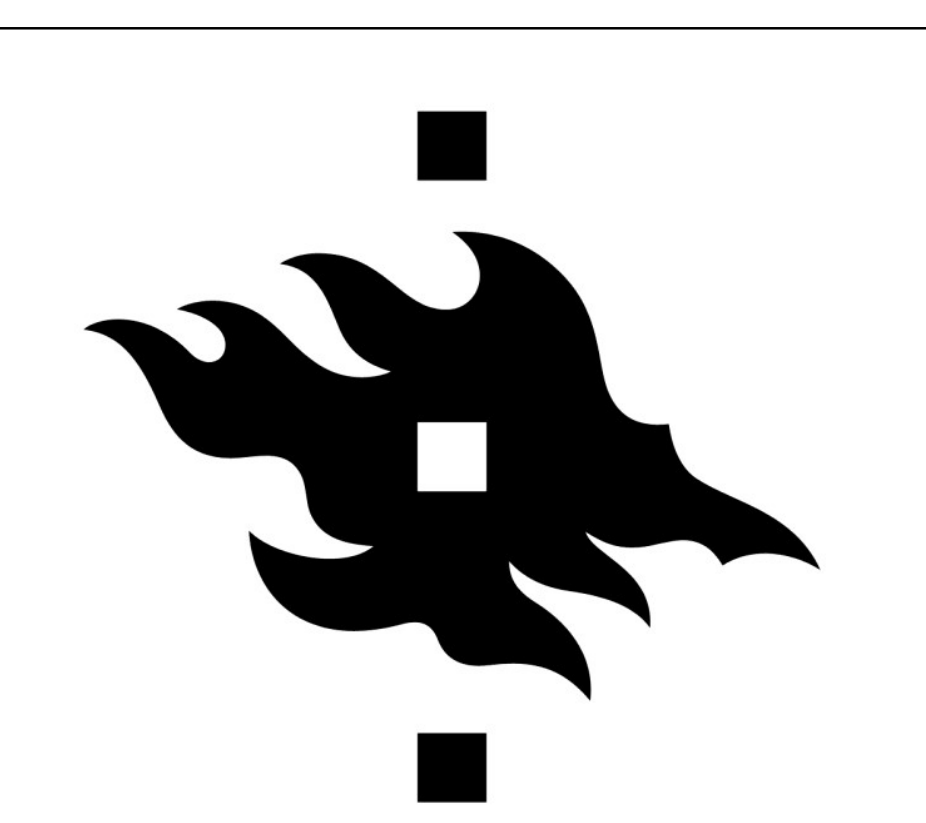

UNIVERSITY OF HELSINKI

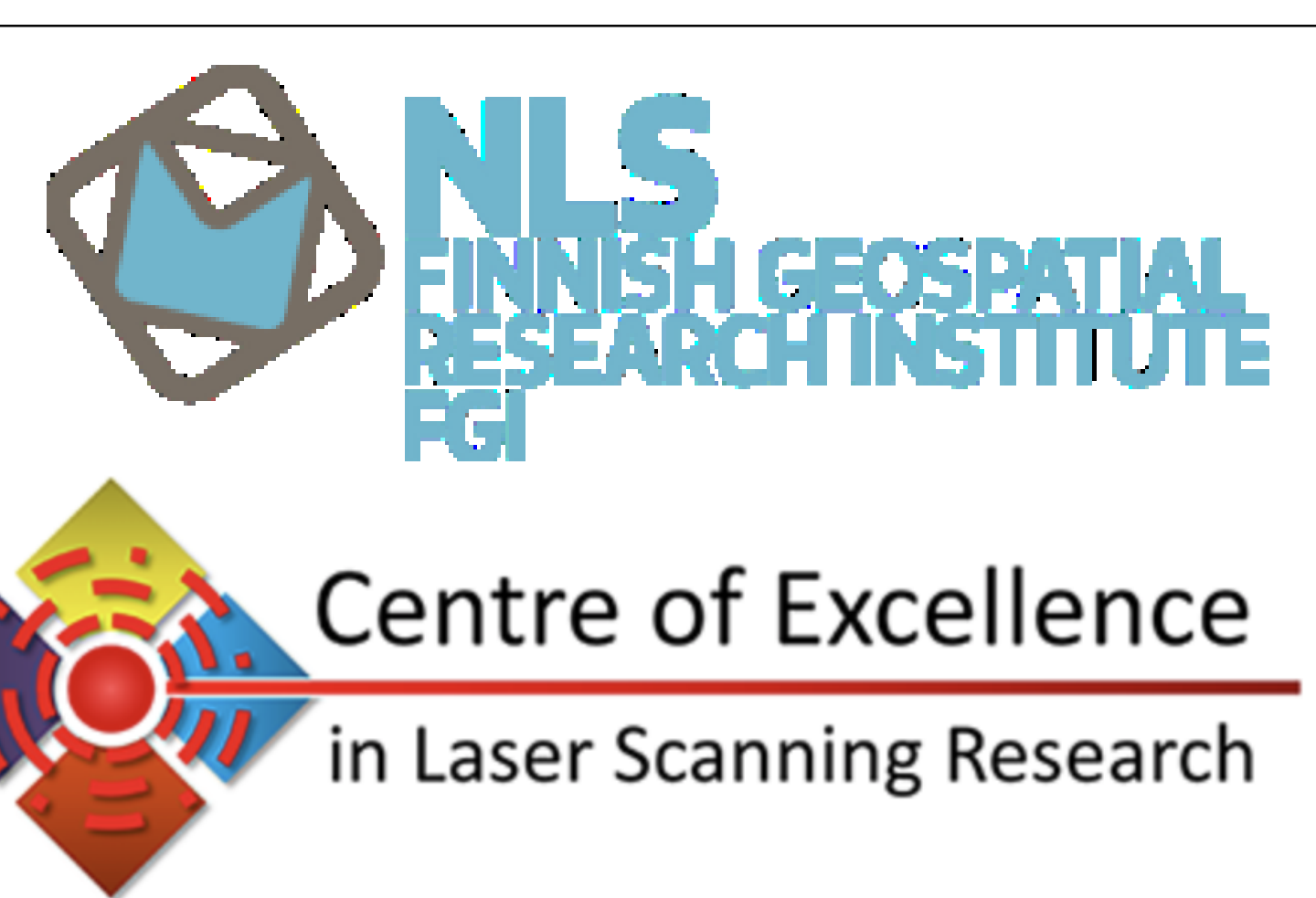

